\title{
Treatment Parameters of Photobiomodulation in the Prevention of Non-surgical Cancer Treatment- Induced Oral Mucositis: A Review of Preclinical Studies
}

\author{
Alaba Tolulope Agbele ${ }^{1,2,3}{ }^{\circledR}$, Sedigheh Marjaneh Hejazi ${ }^{1,4^{*}}{ }^{(}$, Ahmad Reza Dehpour $^{(\mathbb{D}}$, Razieh

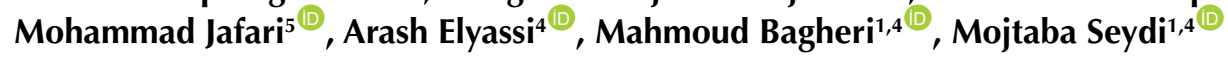 \\ 'Department of Medical Physics and Biomedical Engineering, School of Medicine, Tehran University of Medical \\ Sciences, 1417613151, Tehran, Iran \\ ${ }^{2}$ Department of Basic Medical Sciences, College of Health Sciences and Technology, ljero-Ekiti, Nigeria \\ ${ }^{3}$ Department of Physics, School of Sciences, Federal University of Technology Akure, Nigeria \\ ${ }^{4}$ Bio Optical Imaging Group, Research Center for Molecular and Cellular Imaging, Tehran University of Medical \\ Sciences, Tehran, Iran \\ ${ }^{5}$ Experimental Medicine Research Centre, Tehran University of Medical Sciences, Tehran, Iran
}

\section{*Correspondence to \\ Sedigheh Marjaneh Hejazi, Department of Medical Physics, School of Medicine, \\ Tehran University of Medical Sciences, 1417613151, Tehran, Iran. \\ Tel: +989124841339 \\ Email: mhejazi@sina.tums.ac.ir}

Received: October 4, 2020 Accepted: March 6, 2021 Published online September 29 2021

\begin{abstract}
Introduction: The most important side effect after non-surgery cancer treatment (NSCT) is oral mucositis (OM) which degrades the quality of life. Using photobiomodulation (PBM), formerly known as low-level laser therapy (LLLT), in the prevention of NSCT-induced OM was widely studied. Hence, this review evaluates the efficacy of optical treatment parameters behind the working process of PBM in preventing NSCT-induced OM in preclinical studies.

Methods: Using the PubMed, Scopus and Embase databases, the present study systematically reviewed existing preclinical studies for optical treatment parameters of PBM in preventing NSCTinduced OM in experimental models without restriction on the year of publication.

Results: In total, 51 articles were recognized during the search of the literature, and only 16 research papers were included in this review, taking into consideration the inclusion as well as exclusion benchmarks. The reviewed studies showed that a consensus has yet to be reached on the optimal PBM treatment parameters in preventing NSCT-induced OM. However, a wavelength of $660 \mathrm{~nm}$, a power density of $40 \mathrm{~mW}$ as well as fluence which ranged between 2 and $6 \mathrm{~J} / \mathrm{cm}^{2}$ were mostly utilized in the included studies. Furthermore, the severity of NSCT-induced OM was reduced following PBM application with no reported severe side effects.

Conclusion: The efficacy of PBM with the associated optical parameters is a promising strategy in preventing NSCT-induced OM. However, the optimal parameters of PBM need to be investigated. Keywords: Low-level laser therapy (LLLT); Photobiomodulation (PBM); Oral mucositis; 5-Fluorouracil; NSCT-induced oral mucositis.
\end{abstract}

\section{Introduction}

Oral mucositis $(\mathrm{OM})$ is a painful inflammation and ulceration of the mucosal lining of the inside of the mouth, which often results in a wearing complication associated with cancer regimen., ${ }^{1,2} \mathrm{OM}$ is a serious complication of non-surgery cancer treatment (NSCT) modalities. It comes with acute pain, which affects patients' quality of life (drinking, food intake, weight loss, dehydration, and alteration in taste), and dose-limiting factors that damage the oral epithelium. ${ }^{3-5}$ The pain and discomfort associated with OM negatively affect patient's ability to take medications, which invariably results in the prolonged hospitalization, thereby increasing the cost of cancer treatment. ${ }^{6,7}$

NSCT-induced OM was examined in various experimental models. Chemotherapeutic agents such as 5-fluorouracil (5-FU), methotrexate, and irinotecan were shown to induce mucositis. ${ }^{8-10}$ Thus, many treatment approaches were developed to reduce or prevent severe $\mathrm{OM}$ occurrence. One of such therapeutic strategies is the application of photobiomodulation (PBM), also previously called low-level laser therapy (LLLT). ${ }^{11,12}$

The clinical application of PBM was first established by Mester around the 1960s. This type of modality

Please cite this article as follows: Agbele AT, Hejazi SM, Dehpour AR, Mohammad Jafari R, Elyassi A, Bagheri M, Seydi M. Treatment Parameters of Photobiomodulation in the Prevention of Non-surgical Cancer Treatment-Induced Oral Mucositis: A Review of Preclinical Studies. J Lasers Med Sci. 2021;12:e54. doi:10.34172/jlms.2021.54. 
restricts the laser irradiation intensity by transmitting low fluence to the target tissues as no heat is generated in this process. ${ }^{13} \mathrm{PBM}$ does not increase the tissue temperature due to the power density used, which is much smaller than the intensity needed for photothermal effects to occur. ${ }^{14}$ Red light as well as near-infrared light is used in PBM to revive, mend, and restore multiple physiological processes and repair damage from injuries or diseases. ${ }^{15,16}$ Furthermore, Studies showed that PBM increases fibroblast proliferation, ${ }^{17}$ which also favours collagen synthesis $^{18}$ as well as angiogenesis; ${ }^{19}$ in such a case, it reduces cyclooxygenase-2 (COX-2), tissue necrosis factoralpha (TNF- $\alpha$ ) as well as pro-inflammatory cytokines IL-6 and IL-1 $\beta .20,21$ It also promotes the anti-inflammatory cytokines differentiation, including IL-2, IL-4, IL-8, and IL-10, which acts on the pathway leading to nuclear factor-kappa beta (NF- $\mathrm{KB}$ ) signal transduction. ${ }^{22}$

In addition to preventing or reducing the incidence of NSCT-induced OM, studies have identified other benefits associated with PBM, including the pain treatment of musculoskeletal, skin lesions healing, and anti-inflammatory effects. ${ }^{23-26} \mathrm{PBM}$ does not work alone as some parameters influence its effectiveness in reducing or preventing NSCT-induced OM. Preclinical studies play vital roles in assessing the efficacy of therapeutic modalities such as PBM. Several experimental studies were conducted investigating the ability of PBM to manage NSCT-induced OM. PBM treatment parameters are crucial to obtain desired outcomes. While numerous studies utilized various parameters, there was no consensus about the optimal parameters. The present systematic review aims to assess the efficacy of the optical treatment parameters behind the working process of $\mathrm{PBM}$ to reduce the risk of NSCT-induced OM by considering preclinical studies. These parameters include wavelength, power density, energy density and treatment time. This study will address the following question "what are the common PBM parameters to manage chemotherapyinduced OM?" using PICOS (participants, interventions, comparisons, outcomes, as well as study design).

\section{Methods \\ Search Procedure}

This study was to perform a preclinical small animal review in line with systematic reviews and meta-analyses due to the statement of preferred reporting items (PRISMA). ${ }^{27}$ The electronic database search of PubMed, Embase and Scopus was carried out in April 2020 for research papers investigating the efficacy of PBM against chemotherapyinduced OM by considering experimental animal models, without a restriction on the year of publication. The search keywords were as follows: "low-level laser therapy" and "oral mucositis" and "animals". Furthermore, manual screening of the references of the retrieved studies was conducted to obtain relevant studies.

\section{Inclusion Criteria}

This systematic review was in terms of PICOS: Participants: animals; Intervention: LLLT; Comparisons/ control type: chemotherapy

treated animals only; Outcome variables: wavelength, power density, energy density and treatment time; and Study design: experimental studies.

The inclusion criteria of the retrieved articles were as follows: the studies investigating PBM efficacy of LLLT to prevent chemotherapy-induced $\mathrm{OM}$, published in the English language, the research articles which used chemotherapy, and experimental papers with their complete texts available.

\section{Exclusion Criteria}

Studies were exempted using these benchmarks: research articles that did not use chemotherapy, articles that were not published in the English language, clinical studies, conference abstracts, letters, review articles, editorials, unpublished data, as well as research studies without complete texts available.

\section{Selection of Eligible Study}

The articles retrieved from the electronic database and manual searches were added to EndNote software to remove identical articles. Thereafter, retrieved studies were reviewed by three authors for eligibility. Finally, 16 preclinical articles were selected using the inclusion as well as the exclusion benchmarks.

\section{Extraction of Data}

The authors checked the information extracted from the eligible studies included in the present review. The following information was carefully obtained from each included study: first author name, subject, sample size, NSCT dose, the laser type, wavelength, power, energy, time, as well as spot size. Furthermore, these data were summarized and presented in a tabular form.

\section{Results}

\section{Literature Search}

The flow chart of the included articles in this systematic review is shown in Figure 1 following the PRISMA statement. ${ }^{27}$ The breakdown of the initial search of 51 articles in total is as follows: 48 articles from PubMed, Scopus and Embase and 3 articles obtained from a manual search. Furthermore, 41 articles were engaged after the removal of identical articles. Thereafter, following careful examination and screening of their titles and abstracts as well as applying the inclusion and exclusion criteria, a further 18 articles were excluded. The full texts of the remaining 23 records were assessed. We excluded three articles for non-English language publication, and four articles were further removed for not having full texts. 16 articles were finally considered for review. 


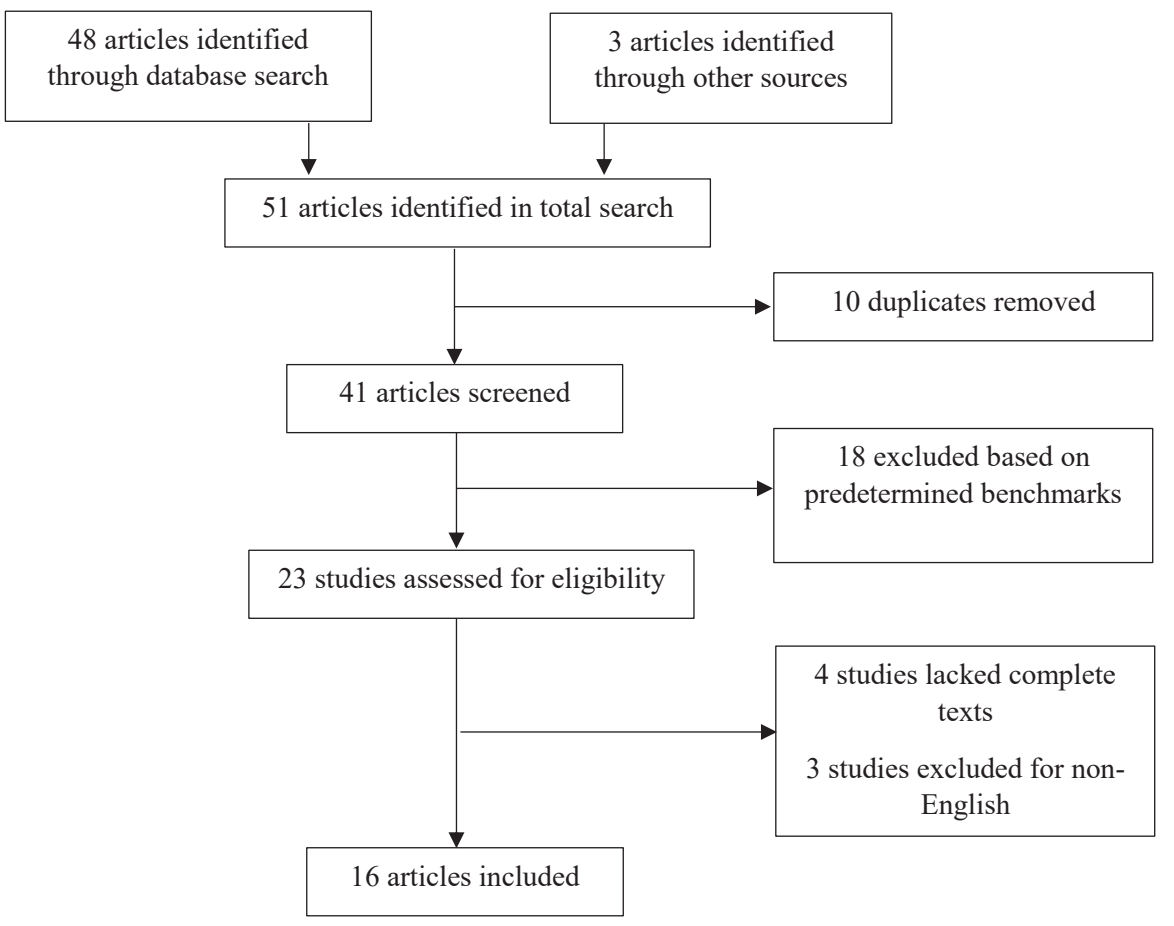

Figure 1. The Flow Chart of the Included Articles in this Systematic Review Following PRISMA Statement.

\section{Study Characteristics}

The studies that were reviewed were published between the years 2007 and 2019, and the summary of these studies is presented in a tabular form (Table 1). Furthermore, the studies were carried out using Sprague-Dawley, Wistar albino, golden/syrian hamsters, mice and rats with a sample size ranging from 8-150. All the studies utilized NSCT as the subjects received 5-FU intraperitoneally. Out of the 16 included studies, 8 studies used NSCT doses of $65-100 \mathrm{mg} / \mathrm{kg}, 2$ studies used $40-80 \mathrm{mg} / \mathrm{kg}$ and 2 studies used $40-60 \mathrm{mg} / \mathrm{kg}$. The laser type mostly used in the included studies is InGaAlP as 7 out of the 16 studies used this. Four studies employed the Nd: YAG diode laser and 3 studies utilized a light-emitting diode (LED). The optical parameters of PBM used in the included studies, such as wavelength, power density, energy density as well as treatment time, were extracted and extensively discussed.

\section{Discussion}

\section{The Wavelength of LLLT in Preclinical Studies}

The laser device has a specific purpose as its use is dependent on the wavelength as well as the output power. Specifically, the wavelength is a factor to be considered in terms of tissue penetration depth. Photoacceptors show distinct responsiveness to individual wavelengths of light. The most effective PBM wavelength ranges from $600 \mathrm{~nm}$ to $1100 \mathrm{~nm}^{28}$ as this is the optical window in tissue. ${ }^{29,30}$

Several experimental studies have reported several PBM wavelengths in the prevention of NSCT-induced
OM (Table 1). The wavelength of $660 \mathrm{~nm}$ was mostly utilized. ${ }^{19,21,31-39}$ Only one study used $630 \mathrm{~nm} .^{7}$ Moreover, higher wavelengths such as $808 \mathrm{~nm},{ }^{33} 810 \mathrm{~nm},{ }^{31,40} 940 \mathrm{~nm},{ }^{41}$ $970 \mathrm{~nm},{ }^{42} 980 \mathrm{~nm},{ }^{31}$ and $1064 \mathrm{~nm},{ }^{36}$ were also utilized. Due to outcomes, smaller differences in wavelengths (632-970 $\mathrm{nm}$ ) had potent therapeutic effects. However, the larger wavelength of $1064 \mathrm{~nm}$ did not show a significant impact. Moreover, wavelengths varying between 632.8-685 nm (visible red) were shown to be effective in preventing NSCT-induced OM at energy densities less than $2 \mathrm{~J} / \mathrm{cm}^{2} .^{43}$

The $660 \mathrm{~nm}$ wavelength utilized in most of the studies can be attributed to the fact that the wavelength increases reactive oxygen species (ROS) if applied before or after the oxidative stimulus. ${ }^{44}$ Besides, it has better absorbance in haemoglobin, closer to tissue cell resonant frequency, and has the ability to influence mitochondrial enzyme activity such as CCO-2, ${ }^{45,46}$ which eventually increases adenosine triphosphate (ATP) level synthesis as well as the mitochondrial activity. ${ }^{46}$ This same wavelength, when used in the LED therapy, increases cell proliferation and migration. ${ }^{47}$

In a study by Campos et $\mathrm{al}^{33}$ involving 150 hamsters, $100 \mathrm{mg} / \mathrm{kg}$ and $65 \mathrm{mg} / \mathrm{kg}$ doses of chemotherapy were administered on day 1 and day 3 respectively. Furthermore, a combination of three wavelengths (LED, $635 \mathrm{~nm}$; PBM, $660 \mathrm{~nm}$ and HPL [high power laser], 808 $\mathrm{nm}$ ) were used. Their results showed a positive outcome in the LED and LLLT groups in which they observed a decrease in the level of TNF- $\alpha$ on day 7 , and the mucosa was totally healed after 10 days. Findings from their study 
Table 1. Summary of PBM Treatment Parameters for The Prevention of NSCT-induced OM in Animal Studies

\begin{tabular}{|c|c|c|c|c|c|c|c|c|c|}
\hline First Author & Subject & $\begin{array}{l}\text { Sample } \\
\text { Size }\end{array}$ & $\begin{array}{l}\text { NSCT Dose } \\
(\mathrm{mg} / \mathrm{kg})\end{array}$ & Laser Type & $\begin{array}{l}\text { Wavelength } \\
\text { (nm) }\end{array}$ & $\begin{array}{l}\text { Power } \\
(\mathrm{mW})\end{array}$ & $\begin{array}{l}\text { Energy }(\mathrm{J} / \\
\left.\mathbf{c m}^{2}\right)\end{array}$ & $\begin{array}{c}\text { Time } \\
(\mathbf{s})\end{array}$ & Spot Size \\
\hline Alinca et $\mathrm{al}^{40}$ & Sprague-Dawley rats & 8 & $65-100$ & Diode laser & 810 & 0.0003 & 18.75 & 5 & $0.08 \mathrm{~cm}^{2}$ \\
\hline Bayer et $\mathrm{al}^{41}$ & Sprague-Dawley rats & 8 & $65-100$ & Diode laser & 940 & 0.001 & 7.14 & 20 & $2.8 \mathrm{~cm}^{2}$ \\
\hline Bostanciklioglu et al ${ }^{36}$ & Adult Wistar-Albino rats & 28 & $65-100$ & $\begin{array}{c}\text { Nd-YAG; } \\
\text { Diode laser; } \\
\text { Diode laser; } \\
\text { Diode laser; }\end{array}$ & $\begin{array}{c}1064 \\
980 \\
810 \\
660\end{array}$ & $\begin{array}{c}0.00025 \\
0.0001 \\
0.00025 \\
0.0001\end{array}$ & $\begin{array}{c}8 \\
8.3 \\
8.04 \\
8\end{array}$ & $\begin{array}{c}9 \\
10 \\
9 \\
60\end{array}$ & $\begin{array}{l}0.28 \mathrm{~cm}^{2} \\
0.12 \mathrm{~cm}^{2} \\
0.28 \mathrm{~cm}^{2} \\
0.75 \mathrm{~cm}^{2}\end{array}$ \\
\hline Campos et $\mathrm{al}^{33}$ & Golden Syrian hamsters & 150 & $65-100$ & $\begin{array}{c}\text { LED; } \\
\text { InGaAIP; } \\
\text { GaAlAs; }\end{array}$ & $\begin{array}{l}635 \\
660 \\
808\end{array}$ & $\begin{array}{c}120 \\
40 \\
0.001\end{array}$ & $\begin{array}{c}1.3 \\
6 \\
10\end{array}$ & $\begin{array}{c}10 \\
6 \\
10\end{array}$ & $\begin{array}{c}1 \mathrm{~cm}^{2} \\
0.04 \mathrm{~cm}^{2} \\
-\end{array}$ \\
\hline Cotomacio et $\mathrm{al}^{32}$ & Syrian hamsters & 18 & $65-100$ & $\begin{array}{c}\text { MMOptics }^{\circledR} \text { : } \\
\text { Laser 1; } \\
\text { Laser 2; } \\
\text { Laser 3; }\end{array}$ & $\begin{array}{l}660 \\
660 \\
660\end{array}$ & $\begin{array}{l}40 \\
40 \\
40\end{array}$ & $\begin{array}{c}6 \\
25 \\
24\end{array}$ & $\begin{array}{c}6 \\
25 \\
6\end{array}$ & $\begin{array}{l}0.04 \mathrm{~cm}^{2} \\
0.04 \mathrm{~cm}^{2} \\
0.04 \mathrm{~cm}^{2}\end{array}$ \\
\hline Cruz et a ${ }^{34}$ & Hamsters & 54 & $65-100$ & $\begin{array}{c}\text { Low-power- } \\
\text { laser }\end{array}$ & 660 & 40 & 120 & $2^{*}$ & $0.037 \mathrm{~cm}^{2}$ \\
\hline Curra et $\mathrm{al}^{35}$ & Golden Syrian hamsters & 96 & $65-100$ & InGaAIP & 660 & 40 & 6 & 6 & $0.04 \mathrm{~cm}^{2}$ \\
\hline Franca et al ${ }^{19}$ & Hamsters & 24 & $65-100$ & GaAlAs & 660 & 30 & 1.2 & 40 & $2 \mathrm{~mm}^{2}$ \\
\hline Freire et $\mathrm{al}^{37}$ & Golden Syrian hamsters & 40 & $60-90$ & $\begin{array}{l}\text { InGaAIP laser; } \\
\text { LED; }\end{array}$ & $\begin{array}{l}660 \\
670\end{array}$ & $\begin{array}{c}40 \\
150\end{array}$ & $\begin{array}{c}4.8 \\
4\end{array}$ & $\begin{array}{l}30 \\
16\end{array}$ & $\begin{array}{c}4 \mathrm{~mm}^{2} \\
0.5 \mathrm{~cm}^{2}\end{array}$ \\
\hline Lara et $\mathrm{al}^{48}$ & Wistar rats & 45 & $50-60$ & GaAlAs & 780 & 70 & 4 & NR & NR \\
\hline Lopes et $\mathrm{al}^{21}$ & Hamsters & 48 & $40-80$ & $\begin{array}{c}\text { InGaAIP } \\
\text { L1; } \\
\text { L2; }\end{array}$ & $\begin{array}{l}660 \\
660\end{array}$ & $\begin{array}{c}35 \\
100\end{array}$ & $\begin{array}{l}E_{t}=10.48 \mathrm{~J} \\
E_{t}=11.12 \mathrm{~J}\end{array}$ & $\begin{array}{c}16 \\
6\end{array}$ & $\begin{array}{l}600 \mu \mathrm{m} \\
600 \mu \mathrm{m}\end{array}$ \\
\hline Lopes et $\mathrm{al}^{39}$ & Hamsters & 48 & $40-80$ & $\begin{array}{l}\text { InGaAIP } \\
\text { L1: } \\
\text { L2 }\end{array}$ & $\begin{array}{l}660 \\
660\end{array}$ & $\begin{array}{c}35 \\
100\end{array}$ & $\begin{array}{l}E_{t}=10.48 \mathrm{~J} \\
E_{t}=11.12 \mathrm{~J}\end{array}$ & $\begin{array}{c}16 \\
6\end{array}$ & $\begin{array}{l}600 \mu \mathrm{m} \\
600 \mu \mathrm{m}\end{array}$ \\
\hline Lopes et $\mathrm{al}^{38}$ & Hamsters & 72 & $40-60$ & InGaAIP & 660 & 40 & 6.6 & 6 & $0.036 \mathrm{~cm}^{2}$ \\
\hline Ottaviani et $a^{42}$ & Mice & 32 & 60 & $\begin{array}{c}\text { Diode laser; } \\
\text { LPLT: } \\
\text { HPLT: }\end{array}$ & $\begin{array}{l}635 \\
970\end{array}$ & $\begin{array}{c}2.5 \\
5\end{array}$ & $\begin{array}{c}0.375 \\
375\end{array}$ & $\begin{array}{l}30 \\
30\end{array}$ & $\begin{array}{l}0.5 \mathrm{~cm}^{2} \\
0.5 \mathrm{~cm}^{2}\end{array}$ \\
\hline Sacono et $\mathrm{al}^{7}$ & Golden Syrian hamsters & 32 & $60-90$ & LED & 630 & 160 & 12 & 37.5 & $0.8 \mathrm{~cm}^{2}$ \\
\hline Thieme et $\mathrm{al}^{31}$ & Rats & 54 & $40-60$ & $\begin{array}{l}\text { InGaAIP } \\
\text { IO (CW): } \\
\text { EO(PM): }\end{array}$ & $\begin{array}{c}660 \\
810+980\end{array}$ & $\begin{array}{c}100 \\
2000\end{array}$ & $\begin{array}{c}6 \\
6.11,12.22\end{array}$ & $\begin{array}{c}2.4 \\
15,30\end{array}$ & $\begin{array}{l}0.04 \mathrm{~cm}^{2} \\
4.91 \mathrm{~cm}^{2}\end{array}$ \\
\hline
\end{tabular}

Abbreviations: NSCT, non-surgery cancer treatment; Nd-YAG, neodymium-doped yttrium aluminium garnet; LED, light-emitting diode; InGaAIP, indiumgallium-aluminium-phosphide; GaAIAs, gallium aluminium-arsenide; Et, total energy; LPLT, low-power laser therapy; HPLT, high-power laser therapy; IO, intraoral; EO, extraoral; CW, continuous wave mode; PM, pulse mode; NR, not reported; *, time reported in minutes.

showed that the LED $(635 \mathrm{~nm})$ and LLLT $(660 \mathrm{~nm})$ are effective in reducing OM severity by speeding up the tissue restoration mechanism and preventing the action of inflammation. This result was similar to studies carried out by Curra et al, ${ }^{35}$ Freire et al, ${ }^{37}$ and Franca et al. ${ }^{19}$ In these studies, a wavelength of $660 \mathrm{~nm}$ was utilized, with their results showing that LED/PBM therapy at this wavelength stimulated the process of repair and reduced the severity of OM by activating the NF- $\kappa \beta$ pathway. Studies ${ }^{38,39,42}$ also showed similar results at wavelengths of $660 \mathrm{~nm}$ and 970 nm.

In a study by Bostanciklioglu et al, ${ }^{36} 28$ adult WistarAlbino rats received $100 \mathrm{mg} / \mathrm{kg}$ and $65 \mathrm{mg} / \mathrm{kg}$ doses of chemotherapy on days 1 and 3 respectively, in addition to a combination of different LLLT wavelengths (660, 810,980 , and $1064 \mathrm{~nm}$ ). A substantial reduction in gene expressions was observed at wavelengths of 660,810 and $980 \mathrm{~nm}$. A similar outcome for a wavelength of $780 \mathrm{~nm}$ was obtained in a study by Lara et $\mathrm{a}^{48}$ in which the laser group was not really effective in preventing OM in rats. In a later study by Cruz et $\mathrm{al},{ }^{34}$ this same wavelength $(660 \mathrm{~nm})$ was found to be effective in ameliorating OM severity, but application time was extended.

\section{Power Density Used in Preclinical Studies}

In the prevention of NSCT-induced OM, PBM power ranging from $5-2000 \mathrm{~mW}$ was utilized in numerous studies. It was shown that lower power density is more effective than higher power density. ${ }^{49}$ However, when the power density is insufficiently coupled with a shorter treatment time, no meaningful effect will be recorded, and at the same time when a large amount of power 
density is applied at a much higher treatment time, this leads to inhibitory effects. ${ }^{30,50}$ This suggests that there must be a balance between too low power/time and high power/time so as to achieve a much beneficial effect on the tissue. Moreover, we may have a situation whereby the low power density is given at a much longer treatment time, thereby leading to many beneficial effects rather than inhibitory as the wavelength, the type of tissue and the pulse parameters can influence this effect.

Furthermore, $40 \mathrm{~mW}$ was commonly used $32-35,37,38$ followed by $100 \mathrm{~mW}-160 \mathrm{~mW} .^{7,21,31,33,37,39}$ A study by Freire et $\mathrm{al}^{37}$ compared an LED $(670 \mathrm{~nm}, 150 \mathrm{~mW})$ and a Laser $(660 \mathrm{~nm}, 40 \mathrm{~mW})$ for the control of OM following NSCT induction. Their results showed that both the laser and the LED effectively stimulated the process of repair and reduced OM lesions and their development.

In another study, Ottaviani and colleagues ${ }^{42}$ compared low-power laser therapy (LPLT; $635 \mathrm{~nm}, 2.5 \mathrm{~mW}$ ) and high-power laser therapy (HPLT; $970 \mathrm{~nm}, 5 \mathrm{~W}$ ). They observed that both LPLT and HPLT, specifically the HPLT, enhanced and speeded up the healing action of OM. They concluded that the HPLT healed and enhanced the process of inflammation as compared to LPLT.

In a later study by Campos and colleagues, three different light therapy protocols were compared to treat NSCT-induced OM (LED: 635 nm, 120 mW; LLLT: 660 $\mathrm{nm}, 40 \mathrm{~mW}$; and HPL: $808 \mathrm{~nm}, 1 \mathrm{~W}) .^{33}$ Their results indicated that the LED and LLLT treatment were foremost in reducing $\mathrm{OM}$ severity. Moreover, it accelerated the repair process of tissue and decreased the process of inflammation. Furthermore, a study by Lopes et al. compared two laser power densities of $35 \mathrm{~mW}$ and 100 $\mathrm{mW} .^{21}$ Their result indicated that the $35 \mathrm{~mW}$ laser showed a peak OM severity reduction than the $100 \mathrm{~mW}$ laser by a significantly lower level of COX-2 staining. In their study, the low-intensity laser therapy reduced OM severity by reducing COX-2 levels and its associated inflammatory response. In a further study by the same researchers, it was reported that PBM at $16 \mathrm{~s}$ time of application reduced OM severity by increasing collagen. ${ }^{39}$ Hence, it can be implied that PBM promotes wound healing and possesses an anti-inflammatory effect as it supports the reduction in neutrophil infiltrate.

\section{Energy Density Used in Preclinical Studies}

Energy density is the most potent parameter in laser $\mathrm{PBM}$ as it estimates the actual energy received by the target tissue. This is often referred to as the fluence ( $\mathrm{J} /$ $\mathrm{cm}^{2}$ ) which means the dose; however, some scholars also referred to energy in joules as dose. ${ }^{30}$

The energy of a laser involved depends solely on the wavelength of the laser, the state and depth of the target tissue, tissue type, pigmentation, acute or chronic problem as well as the treatment technique used (i.e. contact and non-contact modes). Moreover, the laser radiation is determined by its power density (also known as irradiance), power, time and treatment intervals. ${ }^{51}$ In the same vein, it has been stated that there is a high degree of proof indicating that the irradiance and the fluence are the key variables for the efficacy of PBM. ${ }^{52}$

Furthermore, it is better noted that PBM is biphasic as this is used to illustrate the dose expected as a response to light at the cellular level. This implies that when insufficient energy is applied, there will be no response showing that the threshold has not been reached. On the other hand, when higher energy is applied, bioinhibition will occur. ${ }^{50,52} \mathrm{PBM}$ also favours lower doses in wound healing by accelerating the cutaneous tissues as a result of biphasic dose response. ${ }^{53}$

Several preclinical studies have reported several energy densities of PBM in preventing NSCT-induced OM. The energy densities used range from 1.2 to $375 \mathrm{~J} / \mathrm{cm}^{2}$. The energy density of $6 \mathrm{~J} / \mathrm{cm}^{2}$ was mostly utilized. . $^{32,33,35,38}$ Higher doses of energy densities, $18.75 \mathrm{~J} / \mathrm{cm}^{2},{ }^{40} 25 \mathrm{~J} / \mathrm{cm}^{2},{ }^{32}$ $120 \mathrm{~J} / \mathrm{cm}^{2},{ }^{34}$ as well as $375 \mathrm{~J} / \mathrm{cm}^{2},{ }^{42}$ have also been used. Thieme et $\mathrm{al}^{31}$ compared the effect of intraoral (IO) with $6 \mathrm{~J} / \mathrm{cm}^{2}$ of fluence (continuous wave mode) and extraoral (EO) at the fluence of $6 \mathrm{~J} / \mathrm{cm}^{2}$ as well as $12 \mathrm{~J} / \mathrm{cm}^{2}$ (pulsed mode) diode laser irradiation on $\mathrm{OM}$ induced by $5-\mathrm{FU}$ in rats. PBM accelerated the healing process without a reduction in the level of ROS generated. It also showed higher antioxidant levels. Furthermore, the protein damage marker was greatly reduced in the EO $6 \mathrm{~J} / \mathrm{cm}^{2}$ LLLT protocol. The EO diode laser showed positive effects as compared with the IO in OM-induced rats. EO with an energy density of $6 \mathrm{~J} / \mathrm{cm}^{2}$ showed the most promising results among the EO protocols. Moreover, promising outcomes were also observed from studies by Campos et $\mathrm{al}^{33}$ (at $6 \mathrm{~J} / \mathrm{cm}^{2}$ and $660 \mathrm{~nm}$ ), Bayer et $\mathrm{al}^{41}$ (at $7.14 \mathrm{~J} / \mathrm{cm}^{2}$ and $940 \mathrm{~nm})$, Cotomacio et $\mathrm{al}^{32}\left(6 \mathrm{~J} / \mathrm{cm}^{2}\right.$ showed better result at a wavelength of $660 \mathrm{~nm}$ ), and Curra et $\mathrm{al}^{35}$ (6 $\mathrm{J} / \mathrm{cm}^{2}$ and $660 \mathrm{~nm}$ ), in which the activation of NF- $\mathrm{BB}$ pathway greatly reduced the severity of OM lesions. Furthermore, in most of the preclinical studies reviewed, fluence of $4 \mathrm{~J} / \mathrm{cm}^{2}$ and $6 \mathrm{~J} / \mathrm{cm}^{2}$ had a better treatment response and reduced the prevalence as well as the level of OM severity induced by chemotherapy. However, PBM with the fluence of $24 \mathrm{~J} / \mathrm{cm}^{2}$ and $25 \mathrm{~J} / \mathrm{cm}^{2}$ at a $660 \mathrm{~nm}$ wavelength could not ameliorate the incidence of NSCTinduced $\mathrm{OM}$ unlike the result obtained at $6 \mathrm{~J} / \mathrm{cm}^{2}$ using the same wavelength by Cotomacio et al. ${ }^{32}$ Similarly, in a study by Cruz et al, ${ }^{34}$ energy density of $120 \mathrm{~J} / \mathrm{cm}^{2} \mathrm{did}$ not show a promising effect in reducing the severity of NSCTinduced OM.

\section{Treatment Time}

This is the allowed interval through which the energy is delivered to the target tissue when it is exposed to light. ${ }^{54}$ When the treatment time is too short, the effect may not be meaningful, and applying a longer time does not 
necessarily mean that a beneficial effect will be achieved, rather this may lead to inhibitory effects. ${ }^{30,55}$ To achieve a beneficial effect, the time of application needs to be well balanced between the power density and the fluence.

The treatment time of the PBM device is relative to the mode of application of the device (either punctual or scan mode). Franca et $\mathrm{al}^{19}$ reported a total time of application of $40 \mathrm{~s}$ per day. In most studies, application times ranging from $6-60 \mathrm{~s}$ were utilized. ${ }^{34,36,40-42}$ Furthermore, the majority of the studies used the PBM therapy devices in the continuous wave mode, ${ }^{21,31-34,38,39,41,}$ ${ }^{42}$ while Bostanciklioglu et $\mathrm{al}^{36}$ and Thieme et $\mathrm{al}^{31}$ utilized the combination of both continuous wave and pulsed modes. No study has reported the application time effect of different PBM devices on the treatment of NSCTinduced OM.

\section{Conclusion}

For the effective control of NSCT-induced OM, treatment parameters of PBM, including wavelength, power density, energy, energy density and time of application, play key roles, thereby ensuring that the therapeutic benefits following NSCT are maximized. Moreover, from reviewed preclinical studies, a consensus has yet to be reached on the optimal treatment parameters of PBM for the prevention of NSCT-induced OM; however, the wavelength of $660 \mathrm{~nm}$, the power density of $40 \mathrm{~mW}$ and fluence ranging between 2 and $6 \mathrm{~J} / \mathrm{cm}^{2}$ were mostly utilized. Most included preclinical studies had variation in laser devices, wavelength, energy and time. Thus, there would be a need for future studies investigating the optimal treatment parameters of PBM. Furthermore, more comparative studies on these parameters would open up more insights.

Most importantly, the treatment parameters of PBM were productive in ameliorating the OM severity induced by chemotherapy with minimal side effects. However, future preclinical studies using larger sample sizes would be more desirable. Finally, the efficacy of PBM with the associated treatment parameters is a promising strategy in preventing $\mathrm{OM}$ induced by chemotherapy.

\section{Ethical Considerations}

Not applicable.

\section{Conflict of Interests}

The authors declared no conflicts of interest.

\section{Acknowledgment \\ Tehran University of Medical Sciences, Tehran-Iran, supported this research with grant number [IR.TUMS.VCR. REC.1399.278].}

\section{References}

1. Sonis ST. A biological approach to mucositis. J Support Oncol. 2004;2(1):21-32.
2. Sonis ST, Elting LS, Keefe D, Peterson DE, Schubert M, Hauer-Jensen M, et al. Perspectives on cancer therapyinduced mucosal injury: pathogenesis, measurement, epidemiology, and consequences for patients. Cancer. 2004;100(S9):1995-2025. doi:10.1002/cncr.20162

3. Nicolatou-Galitis O, Sarri T, Bowen J, Di Palma M, Kouloulias VE, Niscola P, et al. Systematic review of antiinflammatory agents for the management of oral mucositis in cancer patients. Support Care Cancer. 2013;21(11):31793189. doi:10.1007/s00520-013-1847-y

4. Villa A, Sonis ST. Mucositis: pathobiology and management. Curr Opin Oncol. 2015;27(3):159-164. doi:10.1097/ CCO.0000000000000180

5. Ala M, Jafari RM, Ala M, Agbele AT, Hejazi SM, Tavangar $\mathrm{SM}$, et al. Sumatriptan alleviates radiation-induced oral mucositis in rats by inhibition of NF-kB and ERK activation, prevention of TNF- $\alpha$ and ROS release. Arch Oral Biol. 2020;119:104919. doi:10.1016/j.archoralbio.2020.104919

6. Worthington H, Clarkson J. Prevention of oral mucositis and oral candidiasis for patients with cancer treated with chemotherapy: cochrane systematic review. J Dent Edu. 2002;66(8):903-911. doi: 10.1002/j.00220337.2002.66.8.tb03559.x

7. Sacono NT, Costa CA, Bagnato VS, Abreu-e-Lima FC. Light-emitting diode therapy in chemotherapyinduced mucositis. Lasers Surg Med. 2008;40(9):625-633. doi:10.1002/lsm.20677

8. Stringer AM, Gibson RJ, Logan RM, Bowen JM, Yeoh AS, Hamilton J, et al. Gastrointestinal microflora and mucins may play a critical role in the development of 5-fluorouracil-induced gastrointestinal mucositis. Exp Biol Med. 2009;234(4):430-441. doi:10.3181/0810-RM-301

9. Pereira VB, Melo AT, Assis-Júnior EM, Wong DV, Brito GA, Almeida PR, et al. A new animal model of intestinal mucositis induced by the combination of irinotecan and 5-fluorouracil in mice. Cancer Chemother Pharmacol. 2016;77(2):323-332. doi:10.1007/s00280-015-2938-x

10. Ribeiro RA, Wanderley CW, Wong DV, Mota JMS, Leite $\mathrm{CA}$, Souza $\mathrm{MH}$, et al. Irinotecan-and 5-fluorouracilinduced intestinal mucositis: insights into pathogenesis and therapeutic perspectives. Cancer Chemother Pharmacol. 2016;78(5):881-893. doi:10.1007/s00280-016-3139-y

11. Schubert MM, Eduardo FP, Guthrie KA, Franquin J-C, Bensadoun R-JJ, Migliorati CA, et al. A phase III randomized double-blind placebo-controlled clinical trial to determine the efficacy of low level laser therapy for the prevention of oral mucositis in patients undergoing hematopoietic cell transplantation. Support Care Cancer. 2007;15(10):1145-1154. doi:10.1007/s00520-007-0238-7

12. Silva GBL, Mendonça EF, Bariani C, Antunes HS, Silva MAG. The prevention of induced oral mucositis with low-level laser therapy in bone marrow transplantation patients: a randomized clinical trial. Photomed Laser Surg. 2011;29(1):27-31. doi:10.1089/pho.2009.2699

13. Chung H, Dai T, Sharma SK, Huang Y-Y, Carroll JD, Hamblin MR. The nuts and bolts of low-level laser (light) therapy. Ann Biomed Eng. 2012;40(2):516-533. doi:10.1007/ s10439-011-0454-7

14. Watson T, Nussbaum E. Electro Physical Agents E-Book: 
Evidence-Based Practice. $13^{\text {th }}$ ed. Elsevier Health Sciences; 2020.

15. Hennessy M, Hamblin MR. Photobiomodulation and the brain: a new paradigm. J Opt. 2016;19(1):013003. doi:10.1088/2040-8986/19/1/013003

16. Migliario M, Sabbatini M, Mortellaro C, Renò F. Near infrared low-level laser therapy and cell proliferation: The emerging role of redox sensitive signal transduction pathways. J Biophotonics. 2018;11(11):e201800025. doi:10.1002/jbio.201800025

17. Lopes K, Campos Velho N, Munin E. A study of low power laser on the regenerative process of Girardia tigrina (Girard, 1850)(Turbellaria; Tricladida; Dugesiidae). Braz J Bio. 2009;69(2):327-332. doi:10.1590/s151969842009000200013

18. Sonis ST, Hashemi S, Epstein JB, Nair RG, Raber-Durlacher JE. Could the biological robustness of low level laser therapy (Photobiomodulation) impact its use in the management of mucositis in head and neck cancer patients. Oral Oncol. 2016;54:7-14. doi:10.1016/j.oraloncology.2016.01.005

19. França CM, França CM, Núñez SC, Prates RA, Noborikawa E, Faria MR, et al. Low-intensity red laser on the prevention and treatment of induced-oral mucositis in hamsters. J Photochem Photobiol B Biol. 2009;94(1):25-31. doi:10.1016/j.jphotobiol.2008.09.006

20. Gavish L, Perez L, Gertz SD. Low-level laser irradiation modulates matrix metalloproteinase activity and gene expression in porcine aortic smooth muscle cells. Lasers Surg Med. 2006;38(8):779-786. doi:10.1002/lsm.20383

21. Lopes NNF, Plapler H, Chavantes MC, Lalla RV, Yoshimura EM, Alves MTS. Cyclooxygenase-2 and vascular endothelial growth factor expression in 5-fluorouracil-induced oral mucositis in hamsters: evaluation of two low-intensity laser protocols. Support Care Cancer. 2009;17(11):1409-1415. doi:10.1007/s00520-009-0603-9

22. Chen AC, Arany PR, Huang Y-Y, Tomkinson EM, Sharma SK, Kharkwal GB, et al. Low-level laser therapy activates NF-kB via generation of reactive oxygen species in mouse embryonic fibroblasts. PloS one. 2011;6(7): e22453. doi:10.1371/journal.pone.0022453

23. Bortoletto R, Silva Nd, Zangaro R, Pacheco M, Da Matta R, Pacheco-Soares C. Mitochondrial membrane potential after low-power laser irradiation. Lasers Med Sci. 2004;18(4):204-206. doi:10.1007/s10103-003-0281-7

24. Bortone F, Santos H, Albertini R, Pesquero J, Costa M, Silva Jr J. Low level laser therapy modulates kinin receptors mRNA expression in the subplantar muscle of rat paw subjected to carrageenan-induced inflammation. Int Immunopharmacol. 2008;8(2):206-210. doi:10.1016/j. intimp.2007.09.004

25. Farivar S, Malekshahabi T, Shiari R. Biological effects of low level laser therapy. J Lasers Med Sci. 2014;5(2) :58-62.

26. Arany P. Craniofacial wound healing with photobiomodulation therapy: new insights and current challenges. J Dent Res. 2016;95(9):977-984. doi:10.1177/0022034516648939

27. Moher D, Liberati A, Tetzlaff J, Altman DG, Prisma Group. Preferred reporting items for systematic reviews and meta-analyses: the PRISMA statement. PLoS Med. 2009;6(7):e1000097. doi:10.1371/journal.pmed.1000097
28. Hamblin MR, Demidova TN. Mechanisms of low level light therapy. Mechanisms for low-light therapy. Paper presented at: International Society for Optics and Photonics. 2006; San Jose, California, United States. doi.10.1117/12.646294

29. Anders JJ, Ketz AK, Wu X. Basic principles of photobiomodulation and its effects at the cellular, tissue, and system levels. In: Riegel R, Godbold J,ed. Laser Therapy in Veterinary Medicine: Photobiomodulation. John Wiley \& Sons; 2017: 36. doi:10.1002/9781119220190.ch5

30. Huang Y-Y, Sharma SK, Carroll J, Hamblin MR. Biphasic dose response in low level light therapy-an update. Dose Response. 2011;9(4):602-618. doi:10.2203/doseresponse.11-009.Hamblin

31. Thieme S, Ribeiro JT, Dos Santos BG, de Almeida Zieger $\mathrm{R}$, Severo MLB, Martins MAT, et al. Comparison of photobiomodulation using either an intraoral or an extraoral laser on oral mucositis induced by chemotherapy in rats. Support Care Cancer. 2020;28(2):867-876. doi:10.1007/s00520-019-04889-9

32. Cotomacio CC, Campos L, de Souza DN, Arana-Chavez VE, Simões A. Dosimetric study of photobiomodulation therapy in 5-FU-induced oral mucositis in hamsters. $J$ Biomed Opt. 2017;22(1):018003. doi:10.1117/1. JBO.22.1.018003

33. Campos L, Cruz ÉP, Pereira FS, Arana-Chavez VE, Simões A. Comparative study among three different phototherapy protocols to treat chemotherapy-induced oral mucositis in hamsters. J Biophotonics. 2016;9(11-12):1236-1245. doi:10.1002/jbio.201600014

34. da Cruz ÉdP, Campos L, da Silva Pereira F, Magliano GC, Benites BM, Arana-Chavez VE, et al. Clinical, biochemical and histological study of the effect of antimicrobial photodynamic therapy on oral mucositis induced by 5-fluorouracil in hamsters. Photodiagnosis Photodyn. 2015;12(2):298-309. doi:10.1016/j.pdpdt.2014.12.007

35. Curra M, Pellicioli ACA, Kretzmann Filho NA, Ochs G, Matte Ú, Sant'Ana Filho M, et al. Photobiomodulation reduces oral mucositis by modulating NF-kB. J Biomed Opt. 2015;20(12):125008. doi:10.1117/1.JBO.20.12.125008

36. Bostanciklioglu M, Demiryürek Ş, Cengiz B, Demir T, Öztuzcu S, Aras MH, et al. Assessment of the effect of laser irradiations at different wavelengths $(660,810,980$, and $1064 \mathrm{~nm}$ ) on autophagy in a rat model of mucositis. Laser Med Sci. 2015;30(4):1289-1295. doi:10.1007/s10103-0151727-4

37. Freire MdRS, Freitas R, Colombo F, Valença A, Marques AMC, Sarmento VA. LED and laser photobiomodulation in the prevention and treatment of oral mucositis: experimental study in hamsters. Clin Oral Investig. 2014;18(3):1005-1013. doi:10.1007/s00784-013-1058-4

38. Lopez TCC, Martins MD, Pavesi VCS, Ferreira LS, Bussadori SK, Moreira MS, et al. Effect of laser phototherapy in the prevention and treatment of chemo-induced mucositis in hamsters. Braz Oral Res. 2013;27(4):342-8. doi:10.1590/ S1806-83242013005000019

39. Lopes NNF, Plapler H, Lalla RV, Chavantes MC, Yoshimura EM, da Silva MAB, et al. Effects of low-level laser therapy on collagen expression and neutrophil infiltrate in 5fluorouracil-induced oral mucositis in hamsters. Lasers Surg Med. 2010;42(6):546-552. doi:10.1002/lsm.20920 
40. Alinca SB, Saglam E, Kandas NO, Okcu O, Yilmaz N, Goncu B, et al. Comparison of the efficacy of low-level laser therapy and photodynamic therapy on oral mucositis in rats. Laser Med Sci. 2019;34(7):1483-1491. doi:10.1007/ s10103-019-02757-w

41. Bayer S, Kazancioglu HO, Acar AH, Demirtas N, Kandas NO. Comparison of laser and ozone treatments on oral mucositis in an experimental model. Laser Med Sci. 2017;32(3):673-677. doi:10.1007/s10103-017-2166-1

42. Ottaviani G, Gobbo M, Sturnega M, Martinelli V, Mano $\mathrm{M}$, Zanconati F, et al. Effect of class IV laser therapy on chemotherapy-induced oral mucositis: a clinical and experimental study. Am J Clin Pathol. 2013;183(6):17471757. doi:10.1016/j.ajpath.2013.09.003

43. Bensadoun R-J, Nair RG. Low-level laser therapy in the prevention and treatment of cancer therapy-induced mucositis: 2012 state of the art based on literature review and meta-analysis. Curr Opin Oncol. 2012;24(4):363-370. doi:10.1097/CCO.0b013e328352eaa3

44. Rupel K, Zupin L, Colliva A, Kamada A, Poropat A, Ottaviani G, et al. Photobiomodulation at multiple wavelengths differentially modulates oxidative stress in vitro and in vivo. Oxid Med Cell Longev. 2018;2018:1-11. doi:10.1155/2018/6510159

45. Amaroli A, Ferrando S, Benedicenti S. Photobiomodulation Affects Key Cellular Pathways of all Life-Forms: Considerations on Old and New Laser Light Targets and the Calcium Issue. J Photochem Photobiol. 2019;95(1):455459. doi:10.1111/php.13032

46. Houreld NN, Masha RT, Abrahamse H. Low-intensity laser irradiation at $660 \mathrm{~nm}$ stimulates cytochrome c oxidase in stressed fibroblast cells. Lasers Surg Med. 2012;44(5):429434. doi:10.1002/lsm.22027

47. Kim M-S, Cho Y-I, Kook M-S, Jung S-C, Hwang Y-H, Kim B-H. Effect of $660 \mathrm{~nm}$ light-emitting diode on the wound healing in fibroblast-like cell lines. Int J Photoenergy. 2015; ID: 916838. doi:10.1155/2015/916838

48. Lara RN, de Melo NS, da Guerra ENS. Macroscopic and microscopic effects of GaAIAs diode laser and dexamethasone therapies on oral mucositis induced by fluorouracil in rats. Oral Hlth Prev Dent. 2007;5(1) :63-71.

49. Wu S, Zhou F, Wei Y, Chen WR, Chen Q, Xing D. Cancer phototherapy via selective photoinactivation of respiratory chain oxidase to trigger a fatal superoxide anion burst. Antioxid Redox Sign. 2014;20(5):733-746. doi:10.1089/ ars.2013.5229

50. Huang Y-Y, Chen AC-H, Carroll JD, Hamblin MR. Biphasic dose response in low level light therapy. Dose Response. 2009;7(4):358-83. doi:10.2203/dose-response.09-027. Hamblin

51. Hawkins D, Abrahamse H. Phototherapy-a treatment modality for wound healing and pain relief. Afr J Biomed Res. 2007;10(2): 99-109. doi:10.4314/ajbr.v10i2.50626

52. Sommer AP, Pinheiro AL, Mester AR, Franke R-P, Whelan HT. Biostimulatory windows in low-intensity laser activation: lasers, scanners, and NASA's light-emitting diode array system. J Clin Laser Med Surg. 2001;19(1):2933. doi:10.1089/104454701750066910

53. Corazza AV, Jorge J, Kurachi C, Bagnato VS. Photobiomodulation on the angiogenesis of skin wounds in rats using different light sources. Photomed Laser Surg. 2007;25(2):102-106. doi:10.1089/pho.2006.2011

54. Rojas JC, Gonzalez-Lima F. Low-level light therapy of the eye and brain. Eye Brain. 2011;3:49-67. doi:10.2147/ EB.S21391

55. Lanzafame RJ, Stadler I, Kurtz AF, Connelly R, Brondon $\mathrm{P}$, Olson D. Reciprocity of exposure time and irradiance on energy density during photoradiation on wound healing in a murine pressure ulcer model. Lasers Surg Med. 2007;39(6):534-542. doi:10.1002/lsm.20519 